\title{
Çapraz Tablolarda Multinomial-Dirichlet Dağılımının Uygulanması: İki Şehir (Ukrayna/Harkiv-Türkiye/Giresun) Öğrencilerinin İnternet Kullanım Sıklığının Karşılaştırılması
}

\author{
Esin $\operatorname{Avc1}^{1 *}$ \\ 1 Giresun Üniversitesi, Fen Edebiyat Fakültesi, İstatistik Bölümü, Giresun, Türkiye
}

Geliş / Received: 16/09/2019, Kabul / Accepted: 20/02/2020

\section{$\ddot{O ̈ z}$}

Medikal ve sosyal çalışmaların bir çoğunda nitelik ifade eden değişkenlerle karşılaşılmaktadır. Frekans ve yüzde ile özetlenen iki veya daha fazla nitel değişken arasındaki bağımlılık ilişkisi, tablolaştırılarak incelenmektedir. Yaygın olarak Ki-Kare bağımsızlık testlerinden faydalanılarak alt kategorileri arasındaki bağımlılık ve birlikte değişimi incelenmektedir. Ancak Ki-Kare testi genel bir sonuç vermekte, farklılığı yaratan alt kategori(ler) oran farklarının incelenmesi ile ortaya konulmaktadır. Alt kategori sayısı arttıkça bu karşılaştırma sayısı $\left(\begin{array}{l}k \\ 2\end{array}\right)$ kombinasyonu kadar olmakta ve her bir karşılaştırmada 1- $\alpha$ kadar güven öngörüldüğünden karşılaştırma sayısı arttıkça kümülatif olarak I. tip hata da artmaktadır. Bu çalışmanın amacı, Multinomial-Dirichlet dağılımından yararlanarak, alt kategori sayısına bakılmaksızın sabit I. tip hata ile oran farklarının karşılaştırmasını yapmaktır. Uygulamada, küçük örnek $(n \leq 25)$ için simülasyon verisinden ve Giresun Üniversitesi Bilimsel Araştırma Projeleri tarafından desteklenen SOS-BAP-A-200515-43 verilerinin bir kısmından yararlanılmıştır. Çalışma neticisinde; Multinomial-Dirichlet dağılımı yaklaşımının özellikle küçük örnek hacmi için daha dar güven aralığına sahip olduğu saptanmıştır.

Anahtar Kelimeler: Çapraz tablo, Multinomial-Dirichlet, Ki-Kare, İki oran farkı, İnternet kullanımı.

\section{Application of Multinomial-Dirichlet Distribution in Contingency Tables: Comparison of Internet Usage Frequency of Two City Students}

\begin{abstract}
In most medical and social studies are encountered with categorical variables. The relationship between two or more categorical variables that summarized by frequency and percentage is determined by tabulating. Commonly, Chi-Square independence tests are used to examine the interdependence and interchange between subcategories. However, the Chi-Square test gives a general result, the subcategory(s) that make the difference are revealed by examining the proportions differences. As the number of subcategories increases, this number of pairwise comparisons is equal to $\left(\begin{array}{l}k \\ 2\end{array}\right)$ and since there is $1-\alpha$ confidence in each comparison, the cumulative type I error increases as the number of pairwise comparisons increases. The aim of this study is to using Multinomial-Dirichlet distribution to compare the proportion differences with fixed type I error, regardless of the number of subcategories. In application, simulation data was obtained for the small sample $(\mathrm{n} \leq 25)$, and a part of Project data that supported by Giresun University Scientific Research Projects (SOS BAP-A-200515-43) was used. As a result; Multinomial-Dirichlet distribution approach has been found to give a narrower confidence interval, especially for small sample size.
\end{abstract}

Keywords: Contingency tables, Multinomial-Dirichlet, Chi Square, Two proportion difference, Internet usage. 


\section{Giriş}

Birçok medikal ve sosyal çalışmalarda nitelik ifade eden değişkenlerle karşılaşılmaktadır. Sadece sinırlı değerler veya kategorilerle ölçülen bu değişkenler kategorik değişken olarak tanımlanmaktadır (Powers ve Xie, 2000). Bu tür değişkenler frekans ve yüzde gibi oranlar ile özetlenmektedir. İki veya daha fazla kategorik değişken arasındaki ilişkiler çapraz tablolarla incelenmektedir.

Çapraz tablolar, kategorik değişken(ler)in alt kategorilerinin veri kümesinde tekrarlanma sayısını gösteren tablolardır (Conover, 1999). Yaygın olarak iki nitel değişkenin alt kategorileri arasındaki bağımlılık ve birlikte değişimin incelenmesi için Karl Pearson tarafindan 1900 yılında önerilen Ki-Kare bağımsızlık testlerinden faydalanılmaktadır. Barlett (1935), Cochran (1954), Fisher (1922) ve Neyman (1949) çapraz tablo ile ilgili testlerin oluşturulmasında önemli katkıda bulunmuşlardır. Ki-Kare testi; genel bir sonuç verdiğinden, farkl1lı̆g 1 yaratan alt kategori(ler) ancak oran farklarının incelenmesi ile ortaya konulmaktadır (Özdamar, 2015). Alt kategori sayısı arttıkça karşılaştırma sayısı $\left(\begin{array}{l}k \\ 2\end{array}\right)$ kombinasyonu kadar olmaktadır. Her bir karşılaş̧ırmada 1- $\alpha$ kadar güven öngörüldüğünden karşılaştırma sayısı arttıkça kümülatif olarak I. tip hata $(\alpha)^{\prime}$ da artmaktadır. Çoklu karşılaştırmalarda I. tip hata ( $\alpha)^{\prime}$ 'nın artmaması için çeşitli yaklaşımlar bulunmaktadır (Aickin ve Gensler, 1996). Bu yaklaşımlar I. tip hata ( $\alpha$ 'nın oldukça azalmasına dolayısıyla da testin gücünün azalmasina neden olmaktadır.

Son y1llarda çapraz tablolarda MultinomialDirichlet dağılım uygulamalarıyla sıklıkla karşılaşılmaktadır. Pullen ve Kumaran (2010), yaş gruplarına göre meme kanserine yakalanma olasilıklarını hesaplanmasında Multinomial-Dirichlet dağılımından yararlanmışlardır. Sangeetha vd. (2012), sıfır içeren (sparse) çapraz tablolarda olasılıkların güven aralıklarının hesaplanmasinda uygulamışlardır. La Rosa vd. (2012), mikrobiyom verileri için MultinomialDirichlet dağılımından yararlanarak güç analizi ve örneklem hacmi belirlemeyi sağlayan bir yöntem geliştirmişlerdir. Chen (2016), çapraz grupların farklılıklarının test edilmesinde Multinomial-Dirichlet dağılımını uygulamıştır.

Bu çalışmanın amacı, Multinomial-Dirichlet dağılımından yararlanarak, alt kategori sayısına bakılmaksızın sabit I. tip hata ile oran farklarının karşılaştırmasını yapmaktır. Multinomial-Dirichlet dağılım yaklaşımının etkinliğinin ortaya konulmasında küçük örnek $(n \leq 25)$ için simülasyon verisi ile Giresun Üniversitesi Bilimsel Araştırma Projeleri tarafindan desteklenen SOS-BAPA-200515-43 verilerinin bir kısmindan yararlanılmıştır. $R$ programının "rjags" paketinde kod yazılarak sonuçlar klasik yöntemle karşılaştırılmıştır.

\section{Materyal ve Metot}

Kategorik değişkenler arasındaki ilişkilerin ortaya konulmasında kullanılan çapraz tablolar, kontenjans tabloları olarak da adlandırılmaktadır. Tablolarda yer alan değerler, her kategorinin kaç kez tekrarlandığını ifade eden sayım verilerinin (frekanslar) matris formudur (Conover, 1999). Ele alınan değişken sayısına göre tablo adlandırılmaktadır. Tablo tek değişkene ait frekanslar içeriyorsa tek-yönlü, iki değiş̧ken için iki-yönlü, üç değiş̧ken için üçyönlü ve daha fazla değişken için çok-yönlü çapraz tablo olarak adlandırılmaktadır. Ele 
alınan değişken sayısının yanı sıra, her bir değişkenin alt kategori sayısı tablonun kaç satır (r) ve sütundan (c) oluşacağını dolayısıyla boyutunu ifade etmektedir. İkiyönlü rxc boyutlu tablonun genel gösterimi Tablo 1'deki gibidir.

Burada;

$\mathrm{N}=\mathrm{n}_{1 .}+\mathrm{n}_{2 .}+\ldots+\mathrm{n}_{\mathrm{r} .}=\mathrm{n} .1_{1}+\mathrm{n}_{.2}+\ldots+\mathrm{n}_{\cdot \mathrm{c}}$

biçimindedir. $\mathrm{Bu}$ tür çapraz tablolarda; her bir örneklemin rasgele, her bir değişken sonucunun karşılıklı bağımsız olduğu ve her bir gözlemin sadece bir alt kategoride yer alacağı varsayılır.

Ele alınan kategorik değişkenlerin ölçüm düzeyine göre (nominal ve ordinal) çeşitli test istatistikleri olmakla birlikte, yaygın olarak iki değişkenin nominal-nominal olma durumuyla karşılaşıldığından, bu değişkenler arasındaki bağımlılığın araştırılmasında 1900 yılında Karl Pearson tarafindan önerilen "Pearson Ki-Kare" bağımsızlık testinden yararlanılır (Arıcıgil Çilan, 2013). rxc çapraz tablolarda birçok satır ve sütun olması nedeniyle tek yönlü hipotez kurulumu uygun olmamaktadır (Conover, 1999). Test edilen hipotezler şu şekilde ifade edilmektedir:

$\mathrm{H}_{0}: p_{1 j}=p_{2 j}=\cdots=p_{r j}$

(Tüm

j'ler için)

$\mathrm{H}_{1}$ : Aynı sütundaki en az iki oran birbirine eşit değildir.

Test istatistiği (2) denklemi ile ifade edilmektedir.

$\chi^{2}=\sum_{i} \sum_{j} \frac{\left(n_{i j}-E_{i j}\right)^{2}}{E_{i j}}=\sum_{i} \sum_{j} \frac{n_{i j}^{2}}{E_{i j}}-N$

Burada, $E_{i j}=n_{j} C_{j} / N$ yokluk hipotezinin doğruluğu altında $\left(\mathrm{H}_{0}\right)$ ile elde edilir ve $(\mathrm{i}, \mathrm{j})$ gözlemine ait beklenen değeri tanımlar.

Test istatistiği, yaklaşık olarak $\alpha$ (I. tip hata) anlaml1lık düzeyinde [(r-1)x(c-1)] serbestlik dereceli $\chi^{2}$ dağılımına sahip olduğu varsayilır.

Tablo 1. İki-yönlü rxc boyutlu tablonun genel gösterimi

\begin{tabular}{|c|c|c|c|c|c|}
\hline \multirow[b]{2}{*}{$\begin{array}{c}\text { Sütun } \\
\text { değişkeni } \\
\text { (Y) }\end{array}$} & \multicolumn{5}{|c|}{ Satır değişkeni (X) } \\
\hline & $\mathrm{X}_{1}$ & $\mathrm{X}_{2}$ & $\cdots$ & $\overline{X_{c}}$ & $\begin{array}{c}\text { Sütun } \\
\text { Toplam }\end{array}$ \\
\hline $\mathbf{Y}_{1}$ & $\mathrm{n}_{11}$ & $\mathrm{n}_{12}$ & $\cdots$ & $\mathrm{n}_{1 \mathrm{c}}$ & $\mathrm{n}_{1}$ \\
\hline $\mathbf{Y}_{2}$ & $\mathrm{n}_{21}$ & $\mathrm{n}_{22}$ & $\ldots$ & $\mathrm{n}_{2 \mathrm{c}}$ & $\mathrm{n}_{2}$. \\
\hline$\vdots$ & $\vdots$ & $\vdots$ & $\cdots$ & $\vdots$ & $\vdots$ \\
\hline $\mathbf{Y}_{\mathbf{r}}$ & $\mathrm{n}_{\mathrm{r} 1}$ & $\mathrm{n}_{\mathrm{r} 2}$ & $\cdots$ & $\mathrm{n}_{\mathrm{rc}}$ & $\mathrm{n}_{\mathrm{r}}$ \\
\hline $\begin{array}{c}\text { Satır } \\
\text { Toplam }\end{array}$ & $\mathrm{n} .1$ & n.2 & 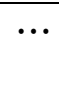 & n.c & n.. $=\mathrm{N}$ \\
\hline
\end{tabular}

$\checkmark \quad E_{i j}{ }^{\prime}$ ler yeterince büyük olduğunda veya $E_{i j}$ 'ler 0,5 'ten büyük ve en az yarısının 1'den büyük olması durumunda $\chi^{2}$ dağılımının yeterli olduğu varsayılmaktadır. 
$\checkmark$ Cochran (1952), $E_{i j}$ 'lerin 1 'den küçük veya $E_{i j}$ 'lerin \%20'sinden fazlasının 5'ten küçük olması durumunda $\chi^{2}$ dağılımının yetersiz olduğunu ifade etmiştir.

$\checkmark E_{i j}$ 'lerin çok küçük olması durumunda, kategoriler birleştirilerek $\chi^{2}$ dağılımının yeterli bir yaklaşım haline gelmesi sağlanabilmektedir ancak burada bilgi kaybına yol açabilmektedir (Conover, 1999).

$\mathrm{H}_{0}$ hipotezinin red edilmesi durumunda, aynı sütundaki hangi iki oranın birbirinden farklı olduğunun saptanmasında bağımsız iki oran arasındaki farkın önemlilik testinden faydalanabilmektedir. Bu durumda olası ikili karşılaştırma sayısı $\left(\begin{array}{l}k \\ 2\end{array}\right)$ ile belirlenir. Test istatistiği;

$Z=\frac{\hat{p}_{k-} \hat{p}_{l}}{\sqrt{\hat{p}_{0}\left(1-\hat{p}_{0}\right)\left(\frac{1}{n_{k}}+\frac{1}{n_{l}}\right)}}, k \neq l=1, \ldots, \mathrm{r}$

ile tanımlanır. Burada; $\hat{p}_{0}=\frac{n_{k j}+n_{l j}}{n_{k .}+n_{l}}$, birleştirilmiş gözlenmiş oran olarak tanımlanmaktadır. Test istatistiği, normal dağglıma sahip olduğu kabul edilir. $\alpha$ anlamlılık (I. tip hata) düzeyinde $Z_{\alpha / 2}$ tablo değeri ile karşılaştırılır. Test değerinin tablo değerinden büyük olması durumunda ilgili iki oranın birbirinden farklı olduğunu gösterir. Ya da iki oran farkına ait güven aralığının sıfır'ı içermemesi durumunda ilgili güven düzeyinde oran farkının anlamlı olduğu yorumu yapılır (Agresti, 1996). Güven aralığg1,

$\hat{p}_{k-} \hat{p}_{l} \pm Z_{\alpha / 2} \times \sqrt{\hat{p}_{0}\left(1-\hat{p}_{0}\right)\left(\frac{1}{n_{k}}+\frac{1}{n_{l}}\right)}$

biçiminde hesaplanır.
Olası tüm ikili karşılaştırmalar test edilerek farklı olan alt kategoriler saptanabilir. Ancak her bir karş1laştırmada 1- $\alpha$ kadar güven öngörüldüğünden karşılaştırma sayısı arttıkça kümülatif olarak I. tip hata $(\alpha)$ da artmaktadır. Ayrıca örneklem hacmi yeterli büyüklükte olmadığında normal dağılım yaklaşım varsayımı sağlanmayabilmektedir.

Örneklem hacminin küçük olması durumunda, Hipergeometrik dağılımı temel alarak olasılik hesaplayan Fisher'in kesin testinden faydalanabilir (Arıcıgil Çilan, 2013).

\subsection{Multinomial-Dirichlet dağılımı}

Multinomial dağglım, binom dağglımının çok değişkenli dağılımıdır. Epidemiyolojik ve Biyoistatistik çalışmalarda, sırasıyla $r$ ve $\mathrm{c}$ alt kategoriye sahip olan $X$ ve $Y$ kategorik değişkenlerin oluşturduğu rxc boyutlu çapraz tablo için en uygun dağılımlardan biri Multinomial dağılımdır.

rxc boyutlu çapraz tabloda ortak olasıl1k dağılımı Multinomial dağılım ile tanımlanır. Burada toplam gözlem sayısını (N) sabit olarak varsayılmaktadır. Ortak olasılık fonksiyonu,

$P[X=i, Y=j]=p_{i j}$,

$i=1,2, \ldots, r$ ve $j=1,2, \ldots, c$

ile tanımlanır. Marjinal olasılık fonksiyonları ise;

$P[X=i]=\sum_{j=1}^{c} p_{i j}=p_{i .}, i=1,2, \ldots, r$

$P[Y=j]=\sum_{i=1}^{r} p_{i j}=p_{. j}, j=1,2, \ldots, c$

ile tanımlanır.

$\sum_{i=1}^{r} \sum_{j=1}^{c} p_{i j}=1$ 
dır. Multinomial dağılım çıkarımları göze sayılarına dayanmaktadır $\quad\left\{n_{i j}: i=\right.$ $1,2, \ldots, r$ ve $j=1,2, \ldots, c\}$.

Olabilirlik fonksiyonu,

$f_{n \mid p}(n ; p)=\left(\begin{array}{c}n . . \\ \mathrm{n}_{11}, \mathrm{n}, \ldots, \mathrm{n}_{r c}\end{array}\right) \prod_{i=1}^{r} \prod_{j=1}^{c} p_{i j} n_{i j}(9)$

ile tanımlanır. Her bir gözenin koşullu dağılımı binom dağılımına sahip olur.

$n_{i j} \mid n . . \operatorname{Binom}\left(n . ., p_{i j}\right)$

Böylece i. satır veya j. sütun için

$n_{i .} \mid n . . \sim \operatorname{Binom}\left(n_{. .}, p_{i .}\right)$ ile

$n_{. j} \mid n . . \sim \operatorname{Binom}\left(n . ., p_{. j}\right)$ ve

$n_{i 1}, \ldots, n_{i c} \mid n_{i .} \sim \operatorname{Multinomial}\left(n_{i .}, \frac{p_{i 1}}{p_{i .}}, \ldots, \frac{p_{i c}}{p_{i .}}\right)$

$n_{1 j}, \ldots, n_{r j} \mid n_{. j} \sim \operatorname{Multinomial}\left(n_{. j}, \frac{p_{1 j}}{p_{. j}}, \ldots, \frac{p_{r j}}{p_{. j}}\right)$

dağılımları tanımlanır (Imperial College London, 2019).

Bayesci yaklaşım; Bayes teoremine dayanan ve parametreyi rasgele değişken olarak tanımlayan bir yaklaşımdır. Bayesci yaklaşımda bir parametrenin olasılığı, o parametreye ait ön bilgi (Önsel dağılım) ile deneysel çalışma sonucunda elde edilen verinin (olabilirlik fonksiyonu) birleştirilmesi (sonsal dağılım) ile elde edilir.

Bayesci yaklaşımda, multinomial dağılıma sahip olabilirlik fonksiyonu için eşlenik önsel dağglım olarak Dirichlet dağılımın seçilmesi Lindley (1964) ve Good (1965) tarafindan önerilmiştir. $\mathrm{Bu}$ dağılım MultinomialDirichlet dağılımı adını almaktadır. Önsel dağılım ile sonsal dağılımın aynı dağılım ailesine sahip olmasına eşlenik dağılım denilmektedir. Multinomial-Dirichlet dağılımı güncellenmiş parametreli Dirichlet dağılımına sahip olmaktadır.

Dirichlet dağılımı, Beta dağılımının çok değişkenli dağılımıdır. Yoğunluk fonksiyonu;

$$
\begin{aligned}
& g\left(p_{1}, \ldots, p_{k} \mid \alpha_{1}, \ldots, \alpha_{k}\right)= \\
& \frac{\Gamma\left(\alpha_{1}, \ldots, \alpha_{k}\right)}{\Gamma\left(\alpha_{1}\right) \ldots \Gamma\left(\alpha_{k}\right)} p_{1}^{\alpha_{1}-1} \ldots p_{k}^{\alpha_{k}-1}
\end{aligned}
$$

ile tanımlanır. Burada $\sum_{m} p_{k}=1, p_{k} \geq 0$ ve $m=1,2, \ldots, k$ dir.

Multinomial-Dirichlet dağılımının güncel parametreli Dirichlet dağılımı,

$\alpha_{m}^{*}=\alpha_{m}+n_{m}$

rxc boyutlu çapraz tablolar için sırasıyla satır için Multinomial-Dirichlet dağılımına ait olabilirlik fonksiyonu,

$n_{i 1}, \ldots, n_{i c} \mid n_{i .} \sim \operatorname{Multinomial}\left(n_{i .}, \frac{p_{i 1}}{p_{i .}}, \ldots, \frac{p_{i c}}{p_{i .}}\right)$

Önsel dağılım,

$p_{i 1}, \ldots, p_{i c} \sim \operatorname{Dirichlet}\left(\alpha_{1}, \ldots, \alpha_{c}\right)$

Sonsal dağglım,

$p_{i 1}, \ldots, p_{i c} \mid \alpha_{1}, \ldots, \alpha_{c} \sim \operatorname{Dirichlet}\left(\alpha_{1}\right.$ $\left.+n_{i 1}, \ldots, \alpha_{c}+n_{i c}\right)$

ve sütun için olabilirlik fonksiyonu,

$n_{1 j}, \ldots, n_{r j} \mid n_{. j} \sim \operatorname{Multinomial}\left(n_{. j}, \frac{p_{1 j}}{p_{. j}}, \ldots, \frac{p_{r j}}{p_{. j}}\right)$

Önsel dağılım,

$p_{1 j}, \ldots, p_{r j} \sim \operatorname{Dirichlet}\left(\alpha_{1}, \ldots, \alpha_{r}\right)$

Sonsal dağılım, 


$$
\begin{array}{r}
p_{1 j}, \ldots, p_{r j} \mid \alpha_{1}, \ldots, \alpha_{r} \sim \operatorname{Dirichlet}\left(\alpha_{1}\right. \\
\left.+n_{i 1}, \ldots, \alpha_{r}+n_{r j}\right)
\end{array}
$$

olur. Tuyl vd. (2009) $\alpha=1$ alınmasinın en iyi bilgi verici olmayan önsel dağılım seçimi olduğunu belirtilmişlerdir.

Son y1llarda bilgisayar programlarının gelişmesiyle, Monte Carlo (MCMC) simülasyon yöntemiyle sonsal dağılımdan simülasyon değerleri doğrudan elde edilmekte ve sonuçlar özetlenmektedir. Bayesci yaklaşımda güven aralığı, parametrenin sonsal dağılımının içerdiği olasılığ1 doğrudan ifade ettiğinden, klasik yöntemden farklı olarak tablo değerine dolayısıyla normal dağılım varsayımına gereksinim duymamaktadır. $\mathrm{Bu}$ durum özellikle küçük örneklem hacimlerinde avantaj sağlamaktadır.

\section{Bulgular}

Multinomial-Dirichlet dağılımı; öncelikle küçük örnek $(n \leq 25)$ için simülasyon ile türetilmiş veri üzerine, daha sonra gerçek veri olan Giresun Üniversitesi Bilimsel Araştırma Projeleri tarafından desteklenen SOS-BAP-A-200515-43 verilerinin bir kısmına uygulanmıştır. $\mathrm{R}$ programının "rjags" paketinde kod yazılarak sonuçlar klasik yöntemle karşılaştırılmıştır. İkiden fazla oran fark karşılaştırılmasının gösterilmesi amaçlandığından $2 \times 3$ boyutlu çapraz tablolar üzerine uygulanmıştır.

\subsection{Simülasyon Verisi}

Simülasyon verisinin oluşturulmasında aşağıdaki aşamalar takip edilmiştir: i. $\left\{n_{1}, \ldots, n_{k}\right\}$ göze değerlerine sahip veri ele alınır.

ii. En çok olabilirlik oran tahmini (EÇOT) $p=\left\{n_{i} / N\right\}$ ile elde edilir ve kitle parametresi olarak ele alınır.

iii. L kez Multinomial (N,p) dağılımından simülasyon ile veri türetilir.

iv. Klasik ve Bayes (MultinomialDirichlet) yaklaşımları için güven aralığ1 oluşturulur.

v. Oran farklarına ait güven aralığg ve mutlak fark değerleri oluşturulur.

Birinci satır toplamı 15 ve ikinci satır toplamı 10 olarak, göze değerleri ise sirasıyla $\{9,5,1\}$ ve $\{3,2,5\}$ seçilmiştir. Buna göre (EÇOT) oran değerleri sırasıyla $\{0.6,0.333,0.067\}$ ve $\{0.3,0.2,0.5\}$ olarak saptanmıştır. $500 \mathrm{kez}$ Multi (15, 0.6,0.333,0.067) ve Multi (10, $0.3,0.2,0.5)$ dağılımından veri türetilerek hem klasik hem de Bayes (Multinomial-Dirichlet) yaklaşımları için güven aralığı oluşturulmuştur. Her bir sütun alt kategorisine göre satır alt kategori oranları arasındaki fark için sonuçlar Tablo 2'de özetlenmiştir.

Bayes yaklaşımında, sonsal dağılımın elde edilmesinde MCMC yöntemi kullanılarak yakınsama 20000 iterasyonda sağlanmış ve ilk 1000 (\%5) simülasyon değerleri Burn (yakma) peryodu kullanılarak atılmıştır. 
Tablo 2. Klasik ve Bayes yöntemine göre oran farklarına ait sonuçlar

\begin{tabular}{lccccc}
\hline Yöntem & $\begin{array}{c}\text { Oran } \\
\text { Farkları }\end{array}$ & $\begin{array}{c}\text { Tahmin } \\
\text { Değeri }\end{array}$ & $\begin{array}{c}\text { Alt Sınır } \\
(\mathbf{A S})\end{array}$ & $\begin{array}{c}\text { Üst Sinır } \\
\text { (ÜS) }\end{array}$ & $\begin{array}{c}\text { Mutlak } \\
\text { Fark } \\
\text { (ÜS-AS) }\end{array}$ \\
\hline Klasik & A: $\mathrm{p}_{11-} \mathrm{p}_{21}$ & 0.300 & -0.077 & 0.677 & 0.754 \\
& B: $\mathrm{p}_{12}-\mathrm{p}_{22}$ & 0.133 & -0.211 & 0.477 & 0.688 \\
& C: $\mathrm{p}_{13-}-\mathrm{p}_{23}$ & -0.433 & $-0,768$ & $-0,099$ & 0.669 \\
\hline Bayes & A: $\mathrm{p}_{11}-\mathrm{p}_{21}$ & 0.232 & -0.109 & 0.540 & 0.649 \\
& B: $\mathrm{p}_{12-} \mathrm{p}_{22}$ & 0.097 & -0.209 & 0.390 & 0.599 \\
& C: $\mathrm{p}_{13-} \mathrm{p}_{23}$ & -0.329 & -0.623 & -0.042 & 0.287 \\
\hline
\end{tabular}

Sütun değişkenine ait üç alt kategori için $\left(\begin{array}{l}3 \\ 2\end{array}\right)=3$ oran farkına ait karşılaştırma yapılmaktadır. Klasik yöntemde her bir oran fark1 karşılaştırmasında için I. tip hata $(\alpha)$ 0.05 ele alındiğında, üç karşılaştırma için hata oran1 $1-(1-\alpha)^{3}=1-(1-$ $0.05)^{3}=0.143$ değerine ulaşmaktadır. Öte yandan klasik yöntemde güven aralığının hesaplanmasında kullanılan tablo değeri (normal dağılım) küçük örneklemlerde dağılımın sağlanmaması nedeniyle doğru sonuçlar vermeyebilmektedir.

Bayesci yaklaşımda güven aralığı, parametrenin sonsal dağılımının içerdiği olasılığ1 doğrudan ifade ettiğinden I. tip hata $(\alpha)$ oranı kümülatif olarak artmamakta ve sabit kalmaktadır.

Tablo 2'den Sütun değişkeninin A ve B alt kategorilerinin satır değişkeninin iki alt kategorilerine göre farklılık göstermediği oluşturulan güven aralığının sıfırı içermesinden ve $\mathrm{C}$ alt kategorisinin ise satır alt kategorilerine göre farkl1lık oluşturduğu güven aralığının sıfırı içermemesinden

saptanmıştır. Alt ve üst sınır mutlak farkları incelendiğinde Bayes yönteminin daha dar güven aralıkları verdiği saptanmıştır. Özellikle oran gibi 0-1 aralığında değer alan bir parametre için, güven aralığının dar olması parametre tahmininde tercih nedeni olmaktadır.

\subsection{Gerçek Veri}

$\mathrm{Bu}$ bölümde, 2015-2016 y1lında yürütücülüğünü üstlendiğim ve Giresun Üniversitesi Bilimsel Araştırma Projeleri tarafindan desteklenen SOS-BAP-A-20051543 verilerinin bir kısmından yararlanılmıştır. Projede, okul çağındaki çocukların gözünden internet güvenliği hakkında Ukrayna/Harkiv - Türkiye/Giresun karşılaştırmalı araştırma yapılmıştır. Giresun'dan 2015 ve Harkiv'den 1275 öğrenci proje çalışmasına katılmıştır. Projede sorulan sorulardan biri olan interneti hangi amaçlar için ve ne sıklıkla kullaniyorsunuz sorusunun alt seçeneklerinden ikisi olan ders ile sosyal medya, Giresun ve Harkiv şehirleri için ele alınmıştır. 
Tablo 3. İnternetin ders amacıyla kullanım sıklığının klasik ve Bayes yöntemine göre iki şehir arasındaki oran farklarına ait sonuçlar

\begin{tabular}{lccccc}
\hline Yöntem & $\begin{array}{c}\text { İki şehir Oran Farkları } \\
\text { (Giresun-Harkiv) }\end{array}$ & $\begin{array}{c}\text { Tahmin } \\
\text { Değeri }\end{array}$ & $\begin{array}{c}\text { Alt Sınır } \\
(\mathbf{A S})\end{array}$ & $\begin{array}{c}\text { Üst Sınır } \\
\text { (ÜS) }\end{array}$ & $\begin{array}{c}\text { Mutlak } \\
\text { Fark } \\
\text { (ÜS-AS) }\end{array}$ \\
\hline Klasik & Asla & -0.031 & -0.045 & -0.018 & 0.027 \\
& Nadiren & 0.063 & 0.029 & 0.097 & 0.068 \\
& Sik S1k & -0.032 & -0.066 & 0.003 & 0.069 \\
\hline Bayes & Asla & -0.031 & -0.045 & -0.018 & 0.027 \\
& Nadiren & 0.063 & 0.028 & 0.097 & 0.069 \\
& Sik S1k & -0.031 & -0.066 & 0.004 & 0.07 \\
& & & & & \\
\hline
\end{tabular}

Ders ile sosyal medya amaçlı kullanım sıklığının Giresun ve Harkiv şehirlerine göre oran fark sonuçları Klasik ve Bayes yöntemi için Tablo 3 ve 4 'te özetlenmiştir.

Tablo 3'ten klasik ve Bayes yöntemlerinin benzer sonuçlar verdiği gözlenmiştir. Ancak yine de klasik yöntemdeki ikili oran karşılaştırmasında kümülatif hata değerinin 0.05 'ten daha büyük (0.143) olmuştur. İnternetin ders amacıyla kullanım sıklığının iki şehir arasında sadece "sık sık" kullanımda farklılık oluşturmadığı (güven aralığı sıfir değerini içermektedir), "Asla" ve "Nadiren" için fark oluşturduğu gözlenmiştir (güven aralığı sıfır değerini içermemektedir). İnterneti ders amaçli kullanmayan Harkiv'deki öğrencilerin oranı Giresun'daki öğrencilerden daha fazla iken, Giresun'daki öğrencilerin oranı Harkiv'deki öğrencilerden nadiren kullanım sıklığı için daha fazla olduğu saptanmıştır. Dolayısıyla
Giresun'daki öğrenciler interneti ders amac1 için Harkiv'deki öğrencilerden daha fazla kullandığı görülmüştür.

Tablo 4'ten klasik ve Bayes yöntemlerinin benzer sonuçlar verdiği gözlenmiştir. Ancak yine de klasik yöntemdeki ikili oran karşılaştırmasında kümülatif hata değerinin 0.05 'ten daha büyük (0.143) olmuştur. İnternetin sosyal medya amaciyla kullanım sıklığının iki şehir arasında farklı olduğu saptanmıştır. İnternetin sosyal medya için "Asla" ve "Nadiren" kullanım sıklığının Giresun'daki öğrencilerin oranının Harkiv'deki öğrencilerden daha fazla olduğu "S1k sık" kullanım sıklığı için ise Harkiv'deki öğrencilerin oranının Giresun'daki öğrencilerden daha fazla olduğu gözlenmiştir. Yani Harkiv'deki öğrenciler interneti sosyal medya için Giresun'daki öğrencilerden daha sıklıkla kullanmaktadır. 
4. Sonuç

Çapraz tablolar, iki veya daha fazla kategorik değişken arasındaki ilişkileri incelemektedir. Yaygın olarak bağımlılık incelenmesi için Ki-Kare bağımsızlık testlerinden faydalanılmaktadır.

Ancak Ki-Kare testi; genel bir sonuç vermekte, alt kategoriler arasındaki farkl1lıkların incelenmesinde oran farklarından yararlanılmaktadır. Alt kategori sayısı arttıkça karşılaştırma sayısı $\left(\begin{array}{l}k \\ 2\end{array}\right)$ kombinasyonu kadar olmaktadir. Her bir karşılaştırmada 1- $\alpha$ kadar güven öngörüldüğünden karşılaştırma sayısı arttıkça kümülatif olarak I. tip hata $(\alpha)$ 'da artmaktadır. Çoklu karşılaştırmalarda I. tip hata $(\alpha)$ 'nın artmaması için çeşitli yaklaşımlar olsa da bu yaklaşımlar I. tip hata $(\alpha)$ 'nın oldukça azalmasına dolayısıyla da testin gücünün azalmasına neden olmaktadır.

Tablo 4. İnternetin Sosyal medya amacıyla kullanım sıklığının klasik ve Bayes yöntemine göre iki şehir arasındaki oran farklarına ait sonuçlar

\begin{tabular}{lccccc}
\hline Yöntem & $\begin{array}{c}\text { İki şehir Oran Farkları } \\
\text { (Giresun-Harkiv) }\end{array}$ & $\begin{array}{c}\text { Tahmin } \\
\text { Değeri }\end{array}$ & $\begin{array}{c}\text { Alt Sınır } \\
(\text { AS })\end{array}$ & $\begin{array}{c}\text { Üst Sınır } \\
\text { (ÜS) }\end{array}$ & $\begin{array}{c}\text { Mutlak } \\
\text { Fark } \\
\text { (ய̈S-AS) }\end{array}$ \\
\hline Klasik & Asla & 0.029 & 0.008 & 0.051 & 0.043 \\
& Nadiren & 0.065 & 0.034 & 0.095 & 0.061 \\
& Sik Sik & -0.094 & -0.127 & -0.060 & 0.067 \\
\hline Bayes & Asla & 0.029 & 0.007 & 0.050 & 0.043 \\
& Nadiren & 0.064 & 0.034 & 0.095 & 0.061 \\
& Sik Sik & -0.093 & -0.127 & -0.060 & 0.067
\end{tabular}

Bu çalışmanın amacı, Multinomial-Dirichlet dağılımından yararlanarak, alt kategori sayısına bakılmaksızın sabit I. tip hata ile oran farklarının karşılaştırmasını yapmaktır.

$\mathrm{Bu}$ amaçla, önce küçük örnek $(\mathrm{n}<25)$ için simülasyon verisine daha sonra gerçek veriye (SOS-BAP-A-200515-43) MultinomialDirichlet dağılımı yaklaşımı $2 \times 3$ boyutlu çapraz tabloya uygulanmıştır.
İki şehrin interneti kullanım sıklığ 1 amaca göre karşılaştırıldığında; Giresun'daki öğrenciler ders, Harkiv'deki öğrenciler sosyal medya için daha sıklıkla kullanmaktadır.

Sonuç olarak; Multinomial-Dirichlet dağılımı yaklaşımının özellikle küçük örnek hacmi için daha dar güven aralığı verdiği saptanmıştır. Ayrıca kümülatif hata; klasik yöntemde \%5'ten \%14'e çıkarken, Multinomial-Dirichlet dağılımı yaklaşımında \%5 olarak kalmıştır. 


\section{Kaynaklar}

Agresti. A. (1996). "An Introduction to Categorical Data Analysis 1st ed.". John Wiley\&Sons. 19-21.

Aickin. M. Gensler. H. "Adjusting for Multiple Testing when Reporting Research Results: The Bonferroni vs Holm Methods". Am J Public Health. 1996. 86(5). 726-728.

Arıcıgil Çilan. Ç. (2013). "Sosyal Bilimlerde Kategorik Verilerle İlişki Analizi”. Pegem Akademi. Ankara. 33-79.

Bartlett. M.S. 1935. "Contingency Table Interactions". Journal of the Royal Statistical Society. 2. 248-252.

Chen. Y. 2016. "A Bayesian DirichletMultinomial Test for Cross-Group Differences". Master of Science. Department of Statistical Science in the Graduate School of Duke University. Durham. NC. 3-12.

Cochran. W. G. 1952. "The $\chi^{2}$ Test of Goodness of Fit". Annals of Mathematical Statistics. 23. 315-345.

Cochran. W.G. 1954.. "Some Methods for Strengthening the Common Chi-Square Tests". Biometrics. 10. 417-451.

Conover. W.J. (1999). "Practical Noneparametric Statistics 3rd ed.”. John Wiley\&Sons. 84-102.

Fisher. R.A. 1922. "On the Interpretation of Chi-Square from Contingency Tables. and the Calculation of P". Journal of the Royal Statistical Society. 85. 87-94.

Good. I. (1965). "The Estimation of Probabilities: An Essay on Modern Bayesian Methods”. MIT Press. 1st edition.
Imperial College London. (2019). wwwf.imperial.ac.uk > Handouts > Notes > Chap6. Son Erişim Tarihi: 04.07.2019

La Rosa. P.. Brooks. J.. Deych. E.. Boone. E.. Edwards. D.. Wang. Q.. Sodergren. E.. Weinstock. G.. and Shannon. W. 2012. "Hypothesis Testing and Power Calculations for Taxonomic-Based Human Microbiome Data". PLoS one. 7. e52078.

Lindley. D. 1964. "The Bayesian Analysis of Contingency Tables". The Annals of Mathematical Statistics. 35.1622-1643.

Neyman. J. 1949. "Contributions to the Theory of the Chi-Square Test". Proceedings of the Berkeley Symposium on Mathematical Statistics and Probability. University of California Press. Berkeley. 239-273.

Özdamar. K. (2015). "SPSS ile Biyoistatistik". Nisan Kitapevi Yayınları. Ankara. 345-355.

Pearson. K. 1900. "On the Criterion that a Given System of Deviations from the Probable in the Case of a Correlated System of Variables is Such that it Can Be Reasonably Supposed to Have Arisen from Random Sampling". Philosophical Magazine. (5)50. 157-175.

Powers. D.A.. Xie. Y. (2000). "Statistical Methods for Categorical Data Analysis". Academic Press. 1-3.

Pullen. G.A.. Kumaran. M. 2010. "Application of Multinomial-Dirichlet Conjugate in MCMC Estimation: A Breast Cancer Study". International Journal of Math. Analysis. 4(41). 2043-2049.

Sangeetha. U.. Subbiah. M.. Srinivasan. M.R. 2012. "Estimation of Confidence Intervals for Multinomial Proportion of Sparse 
Çapraz Tablolarda Multinomial-Dirichlet Dağılımının Uygulanması: İki Şehir Öğrencilerinin İnternet Kullanım Sıklığının Karşılaştırılması

Contingency Tables Using Bayesian

Methods". International Journal of Scientific and Research Publication. 3(4). 1-7.

Tuyl. F.. Gerlach. R.. Mengersen. K. 2009. "Posterior Predictive Arguments in Favor of the Bayes-Laplace Prior as the Consensus Prior for Binomial and Multinomial Parameters". Bayesian Analysis. 2009. 4. 151 $-158$. 